\title{
Improving undergraduate medical education about pain assessment and management: A qualitative descriptive study of stakeholders' perceptions
}

\author{
Pierre-Paul Tellier MD ${ }^{1}$, Emmanuelle Bélanger MSc PhD(c) ${ }^{2}$, Charo Rodríguez MD PhD ${ }^{1}$, \\ Mark A Ware MD MSc ${ }^{1,3}$, Nancy Posel $\mathrm{N} \mathrm{PhD}^{1}$
}

\begin{abstract}
P-P Tellier, E Bélanger, C Rodríguez, MA Ware, N Posel. Improving undergraduate medical education about pain assessment and management: A qualitative descriptive study of stakeholders' perceptions. Pain Res Manag 2013;18(5):259-265.
\end{abstract}

BACKGROUND: Pain is one of the most common reasons for individuals to seek medical advice, yet it remains poorly managed. One of the main reasons that poor pain management persists is the lack of adequate knowledge and skills of practicing clinicians, which stems from a perceived lack of pain education during the training of undergraduate medical students. OBJECTIVE: To identify gaps in knowledge with respect to pain management as perceived by students, patients and educators.

METHODS: A qualitative descriptive study was conducted. Data were generated through six focus groups with second- and fourth-year medical students, four focus groups with patients and individual semistructured interviews with nine educators. All interviews were audiotaped and an inductive thematic analysis was performed.

RESULTS: A total of 70 individuals participated in the present study. Five main themes were identified: assessment of physical and psychosocial aspects of pain; clinical management of pain with pharmacology and alternative therapies; communication and the development of a good therapeutic relationship; ethical considerations surrounding pain; and institutional context of medical education about pain.

CONCLUSION: Participating patients, students and pain experts recognized a need for additional medical education about pain assessment and management. Educational approaches need to teach students to gather appropriate information about pain, to acquire knowledge of a broad spectrum of therapeutic options, to develop a mutual, trusting relationship with patients and to become aware of their own biases and prejudice toward patients with pain. The results of the present study should be used to develop and enhance existing pain curricula content.

Key Words: Medical education; Pain management; Qualitative research

\author{
L'amélioration de la formation médicale de premier \\ cycle sur l'évaluation et la prise en charge de la \\ douleur : une étude descriptive et qualitative des \\ perceptions des intervenants
}

\begin{abstract}
HISTORIQUE : La douleur est l'une des raisons pour lesquelles les gens consultent le plus le médecin, mais elle demeure mal prise en charge. Le manque de connaissances pertinentes et de compétences de la part des cliniciens en exercice est l'une des principales raisons de ce phénomène, qui découle d'un manque perçu de matière sur la douleur pendant la formation des étudiants en médecine au premier cycle.

OBJECTIF : Déterminer les lacunes en matière de prise en charge de la douleur sur le plan des connaissances, telles que les perçoivent les étudiants, les patients et les professeurs.

MÉTHODOLOGIE : Les chercheurs ont procédé à une étude descriptive et qualitative. Ils ont obtenu leurs données auprès de six groupes de travail d'étudiants en médecine de deuxième et quatrième année, de quatre groupes de travail de patients et d'entrevues semi-structurées individuelles auprès de neuf professeurs. Ils ont procédé à l'enregistrement audio de toutes les entrevues et à une analyse thématique inductive.
\end{abstract}

RÉSULTATS : Au total, 70 personnes ont participé à la présente étude. Cinq grands thèmes ont été dégagés : évaluation des aspects physiques et psychosociaux de la douleur, prise en charge clinique de la douleur par la pharmacologie et d'autres thérapies, communication et établissement d'une bonne relation thérapeutique, considérations éthiques entourant la douleur et contexte institutionnel de la formation médicale sur la douleur. CONCLUSION : Les patients, les étudiants et les experts de la douleur participants ont convenu de la nécessité d'une formation médicale plus approfondie sur l'évaluation et la prise en charge de la douleur. Dans le cadre des démarches d'enseignement, il faut enseigner aux étudiants à obtenir de l'information pertinente au sujet de la douleur, à acquérir des connaissances et un large spectre de possibilités thérapeutiques, à entretenir une relation mutuelle de confiance avec les patients et à prendre conscience de leurs propres biais et préjugés envers les patients qui ressentent de la douleur. Les résultats de la présente étude devraient servir à préparer et améliorer le programme sur la douleur.

least in part, from a lack of pain education in training as far as undergraduate medical students are concerned. In fact, attitudes and educational barriers (in both undergraduate and graduate education) have been identified as the most important factors driving appropriate pain management in health care $(11,12)$. Furthermore, it has been demonstrated that modifying the pain curricula can have a significant impact on knowledge and beliefs about pain in health care professionals (13-17). Despite the demonstrated effectiveness of educational efforts regarding pain, shortcomings in pain education in academic centres remain evident. A recent survey of major Canadian universities found that only one-third of health science faculties could identify a designated pain curriculum in their programs (18). Although it appears difficult to believe, the study also found that veterinary schools teach about pain management three to four times more than medical schools

A plausible explanation for this phenomenon is that pain management is not well understood by practicing clinicians. This may stem, at

${ }^{1}$ Department of Family Medicine; ${ }^{2}$ Division of Social and Transcultural Psychiatry; ${ }^{3}$ Alan Edwards Pain Management Unit, Department of Anesthesiology, McGill University, Montreal, Quebec

Correspondence and reprints: Dr Pierre-Paul Tellier, 3600 McTavish Avenue, Montreal, Quebec H3A IX9. Telephone 514-398-3593,

fax 514-398-2559, e-mail pierre-paul.tellier@mcgill.ca 
TABLE 1

\section{Characteristics of participants}

\begin{tabular}{|c|c|c|c|}
\hline \multirow[b]{2}{*}{ Characteristic } & \multirow[b]{2}{*}{ Patients } & \multicolumn{2}{|c|}{ Students } \\
\hline & & Second year & Fourth year \\
\hline \multicolumn{4}{|l|}{ Sex } \\
\hline Male & $3(23)$ & $8(28)$ & $5(26)$ \\
\hline Female & $10(77)$ & $21(72)$ & $14(74)$ \\
\hline \multicolumn{4}{|l|}{ Age range,years, $\mathrm{n}$} \\
\hline $20-29$ & 4 & & \\
\hline 30-39 & 1 & & \\
\hline $40-49$ & 1 & & \\
\hline $50-59$ & 2 & & \\
\hline $60-69$ & 3 & & \\
\hline$>70$ & 1 & & \\
\hline \multicolumn{4}{|l|}{ Personal experience with pain } \\
\hline $\begin{array}{l}\text { Has ever experienced acute pain } \\
\text { themselves }\end{array}$ & & $25(86)$ & $15(79)$ \\
\hline $\begin{array}{l}\text { Has ever experienced chronic pain } \\
\text { themselves }\end{array}$ & & $8(28)$ & $4(21)$ \\
\hline $\begin{array}{l}\text { A family member or friend has } \\
\text { experienced acute pain }\end{array}$ & & $29(100)$ & $14(74)$ \\
\hline $\begin{array}{l}\text { A family member or friend has } \\
\text { experienced chronic pain }\end{array}$ & & $21(72)$ & $14(74)$ \\
\hline $\begin{array}{l}\text { Perceive their pain management to } \\
\text { be inadequate }\end{array}$ & $9(68)$ & & \\
\hline Total number of participants, $n$ & 13 & 29 & 19 \\
\hline
\end{tabular}

Data presented as $n$ (\%) unless otherwise indicated

(a mean of $87 \mathrm{~h}$ versus $16 \mathrm{~h}$, respectively) (18). A survey of North American medical schools confirmed these findings (19). Although Canadian schools fared better than American schools by teaching twice the median number of hours about pain, the authors concluded that pain education is fragmentary and limited (19).

The International Association for the Study of Pain has developed a core curriculum for professional education in pain (20). Nonetheless, barriers to improving education about pain remain, including an overcrowded curriculum in most medical schools and a lack of expertise in pain management among medical faculty $(12,19)$. In addition, respondents to the Canadian survey about pain curricula mentioned that they would like to have access to additional resources for pain curriculum development (eg, more case studies to integrate theoretical notions into clinical practice), as well as interprofessional and web-based resources (18). In fact, while examining proposed curriculum developments about pain, it became apparent that these were almost exclusively based on the perspectives of pain management experts $(16,21)$. The perspectives of other important stakeholders, such as patients and medical students undergoing training, have been remarkably absent from curriculum development initiatives. Medical students and residents are typically only invited to evaluate the curricula once they have been implemented $(14,16,22)$.

To our knowledge, a qualitative study exploring the perspectives of all the important stakeholders to establish important areas of learning about pain has not been performed. The question guiding the present inquiry was stated as follows: What do patients, medical students and pain management educators believe to be important areas of knowledge and skills in the clinical management of pain? Specific attention was devoted to their views regarding the role of adequate communication in pain assessment and management. Beyond simply reiterating the need for more education, the present study aims to identify specific areas of learning in undergraduate medical education that could yield improvements in pain management.

\section{Design}

\section{METHODS}

A qualitative descriptive study was conducted to describe and understand different perspectives about pain management in undergraduate training $(23,24)$. Qualitative description involves an eclectic but coherent combination of data collection, data analysis and representational techniques without a heavy theoretical background, which appears to be a particularly useful methodology to address practical issues of interest to clinicians (23). The privileged technique used for collecting data was qualitative individual and group interviewing with three distinct groups of participants, namely patients, medical students and educators involved in teaching pain management (25). Throughout 2010 and 2011, focus groups with patients and medical students and individual interviews with pain experts were conducted. A focus group is a technique that enables researchers to better understand how participants think and feel about a particular issue by recording the conversations that it generates and documenting points of convergence and divergence (26). The same semistructured interview guide was used with all groups. Individual interviews enable in-depth exploration of the perspective of pain experts. The questionnaire included many questions about the role of communication in the assessment and management of pain. Ethics approval for the research project was obtained from the Institutional Review Board of McGill University (Montreal, Quebec) before the beginning of the study.

\section{Participants and procedures}

A total of four focus groups involving patients were conducted. Two involved small groups, with only two participants attending despite the fact that many had previously confirmed their attendance. This is a vulnerable population with potential health and mobility issues; therefore, the results obtained from these smaller groups were retained in the analysis. The other patient focus groups involved four and five participants, respectively, for a total of 13 participating patients. The patients self-reported a variety of pain-related diagnoses such as arthritis, cancer, fibromyalgia, spine fractures, migraines and multiple sclerosis. Patients were recruited from patient support groups, through announcements in patient newsletters of the Quebec Pain Society, through posters placed in pain clinics and through direct contact with support group leaders.

Focus group interviews were also conducted with medical students at various stages in the medical school curriculum. A total of six focus groups were conducted: three with students who had completed their basic sciences and were just beginning their clinical experience (second-year students); and three with students who had nearly finished their undergraduate medical education (fourth-year students). Six to 10 students attended each focus group. Descriptive statistics regarding the 48 participating students and their personal experiences with pain are summarized in Table 1 . The focus groups were all moderated by the first author (PPT) with the assistance of the second author (EB). Students were recruited through announcements in class by one of the researchers, followed by an e-mail reminder.

Finally, to explore the opinions of experts in pain management, individual interviews were conducted with nine educators in different specialties, namely anesthesiology, palliative medicine, rheumatology and nursing with a specialization in pain management. A focus group involving all the educators was not feasible due to the participants' busy schedules. These individual interviews lasted between $30 \mathrm{~min}$ and $1 \mathrm{~h}$. The second author (EB) conducted the individual interviews with pain experts. A list of individuals involved in pain education was generated by one of the researchers (MW); they were sent a personalized e-mail asking them to participate. Based on the responses, educators with specific backgrounds were solicited in person or by telephone to obtain a more varied sample. In total, 70 stakeholders in medical training about pain were involved in the present study.

\section{Data analysis}

All focus groups and interviews were audiorecorded with the permission of participants and transcribed verbatim. The method of data analysis consisted of inductive thematic analysis (27) performed by the first two authors using HyperRESEARCH 2.8 (ResearchWare Inc, USA) (28). Material was carefully examined and major themes that recurred in answers and conversations across groups of respondents were highlighted without approaching the data with a pre-established 
TABLE 2

\section{Themes and excerpts}

\begin{tabular}{|c|c|c|c|}
\hline Themes & Patients & Students & Educators \\
\hline $\begin{array}{l}\text { Assessment of } \\
\text { pain }\end{array}$ & $\begin{array}{l}\text { "It's your entire life that's upside down } \\
\text { because of the pain, from A to Z." } \\
\text { (Patient } H)\end{array}$ & $\begin{array}{l}\text { "One thing l'm not sure we mentioned in the } \\
\text { definition of pain is how subjective pain } \\
\text { actually is and somebody's... we're } \\
\text { mentioning numbers here like } 10 \text { on } 10,7 \text { on } \\
\text { 10, but somebody's } 10 \text { on } 10 \text { is somebody } \\
\text { else's } 3 \text { on 10." (Fourth-year student, focus }\end{array}$ & $\begin{array}{l}\text { "We have a lot of judgments and we expect people } \\
\text { to look a certain way [...]. There is no one tool } \\
\text { that in and of itself will legitimize what that patient } \\
\text { is reporting to us. And so that alliance and the } \\
\text { assessment process is crucial." (Clinical nurse } \\
\text { specialist) }\end{array}$ \\
\hline
\end{tabular}

Clinical "I wish someone had taken five more management of minutes to find out that I'm someone pain that is not really for meds if I can avoid it and discuss other options instead of just saying $[\ldots]$ here is a prescription." (Patient M)

Communication and the therapeutic relation

"And if the doctor can be honest, if he finds it difficult to find the best combination, then he should express that. He doesn't have to be a god who has the right treatment." (Patient F)

Ethical considerations

"When I get to the hospital they laugh at me and they say it's in my head." (Patient C)

Institutional context of education

\begin{abstract}
"Even with my oncologist, when I told him I was followed in palliative care for the pain, he was relieved. He can deal with your cancer but would rather have you go see someone else to manage the pain." (Patient $A$ )
\end{abstract} group 3)

"We've never learned about things like acupuncture or massage, or cognitivebehavioral therapy for people with pain, or osteopathic manipulation, which apparently is really popular for people with chronic pain." (Fourth-year student, focus group 4)

"Communication with the physician is not just getting a prescription but actually talking about what makes it better, what makes it worse. Having that dialogue with someone who believes you is probably a really good part of the pain management itself." (Secondyear student, focus group 1)

"I feel quite hesitant to take the risk of withholding medication from a patient who would need it in order to prevent another person who is drug-seeking from getting it." (Fourth-year student, focus group 2)

"You know, there seems to be this general attitude that oh well the pain is not going to kill the patient. They can tolerate some. So you know we'll do what we can but it's not the focus of what we're doing here." (Fourth-year student, focus group 3)
"When I first meet patients I make it very clear to them that there is not just one modality to treat chronic pain, that the pain has impacted their lives in many ways, that it often has an effect on their mood and their sleep." (Anesthesiologist)

"Patients are for the most part not insensitive to physicians' attitudes. They're quite good at figuring out if somebody doesn't really care, or when somebody genuinely does care. I think that's one of the main aspects that facilitate communication." (Anesthesiologist)

"This is the art of medicine, there is no right or wrong. You never, ever are going to know whether your interpretation was accurate or not. You just have to be humble in your acceptance of that." (Rheumatologist)

"Once students are on the clinical teaching units if the staff doesn't show interest in symptom management including pain management, the student will gradually lose this ability to ask about pain. So I think that the senior residents and the teaching staff have to demonstrate that pain assessment and management are important." (Palliative care physician) theoretical framework. Themes were first compared between the two researchers who performed the interviews, then discussed in detail with a third member of the research team (CR) until agreement that it provided a faithful description of the original material was reached. Final interpretations were further discussed among all the researchers during a number of research team meetings. The excerpts used as examples of the themes were selected to represent recurrent opinions and ideas.

\section{RESULTS}

Five major themes were identified: the assessment of physical and psychological aspects of pain; the clinical management of pain including pharmacology and alternative therapies; communication and the development of a good therapeutic relationship; ethical considerations that emerge in pain management; and the institutional setting where pain education takes place. The themes were surprisingly similar across patients, medical students and educators; they will, thus, be described successively among the different groups of respondents. Table 2 provides supporting excerpts that will be referred to throughout the discussion of the results.

\section{Assessment of physical and psychological aspects of pain}

The patients who participated in the interviews clearly expressed that their pain was multidimensional and extended beyond physical ailments to have a negative impact on their day-to-day lives. It affected their daily activities and their personal and professional lives, as well as their mood (Table 2). They believed that this should be considered in the assessment process:

It's a matter of listening past the pain scale. It's listening at a multi-

level, saying this pain, how is it affecting your life? (Patient I)
Patients also mentioned how it affected their relationships: You can't handle it anymore, which brings irritability and impatience. (Patient A)

Patients reported many instances of feeling as though their health care providers did not really understand the extent of their pain and suffering. Describing his first visit to a pain clinic, a patient with chronic back pain said that he finally felt heard and understood. As will be explored below, the understanding and attentiveness of their health care providers was crucial to alleviating the pain.

Students also brought up the assessment of the physical and psychosocial aspects of pain (Table 2). They discussed the types of questions that they would ask patients:

What type of pain it is they are having? Is it neuropathic? Is it visceral? Is it acute or chronic? Details to give you a better idea where it is. (Fourth-year student, focus group 2)

Or they would simply use the traditional pain scale:

I would ask the first question, describe the intensity on a scale of 1 to 10. (Second-year student, focus group 6)

Students appeared to be concerned with the importance of exploring its impact on different aspects of patients' lives such as their daily activities and relationships. As a fourth-year student said:

There's also a big psychosocial aspect to it that I think most of us are pretty aware of. (Focus group 4)

While most students were familiar with the complexity involved in the experience of pain, they still found its subjective and emotional nature challenging in clinical assessments. Many longed for a more objective measurement tool. As a fourth-year student jokingly said: 
Just give them a little zap, how much more does it hurt? [...]

Pain is a 7 or 9? (all laughing). Ok no zaps. (Focus group 4)

Being trained within the traditional biomedical model, this satire testifies to the students' discomfort toward the subjectivity of pain assessments and their preference for objective measurements.

Educators concurred that pain, as a subjective experience, does not fit very well in the medical model and, thus, represents a challenge for students and more experienced clinicians alike. They described the different aspects that should be considered when performing a pain assessment, which extends far beyond physical examinations, tests and imaging to consider the psychological and functional impact of the pain. Educators emphasized the importance of addressing the suffering involved in pain:

Pain and suffering is often inseparable for people; patients express it the same way. (Palliative care physician)

In broadening their assessment of pain, an educator reported occasionally uncovering much deeper psychological wounds such as abuse or neglect. They further mentioned that the physical origin of the pain often becomes irrelevant in chronic pain management:

You have to go with what the patient tells you. If they have a lot of suffering then you deal with that. (Anesthesiologist)

They recognized the lack of a tool that would legitimize patients' subjective feelings (Table 2), but added that:

Science now has taught us that patients experience pain in different ways. [...] Science has taught us to respect what the patient is saying. (Rheumatologist)

Overall, the experts attempted to take patients' expressions of pain at face value and to accept its subjective and multidimensional nature.

\section{Clinical management of pain (pharmacological, alternative)}

As demonstrated in Table 1, the majority of participating patients perceived that their pain was not adequately managed. Patients often lacked information about the pharmacological treatments they were prescribed:

I left [the consultation with a prescription], not knowing what pregabalin was because it wasn't explained to me, what it was going to do, or anything like that. (Patient M)

Many wished they had been more involved in the decision-making processes, as expressed in Table 2; one patient wished she had had the opportunity to express her dislike for medication if alternatives exist. Patients also believed that they had to fend for themselves and search for alternative ways to manage their pain on their own. Whenever they had experimented with alternative treatments, such as physical therapy or massage therapy, it was rarely following the suggestions of their physicians.

I find that even physicians who know that support groups exist will not necessarily think of referring you. (Patient E)

In addition, patients explicitly acknowledged the importance of including their emotional responses in the management plan, lest the pain becomes amplified:

They don't always understand that the emotional side plays a huge part in how you cope with your pain, because if your emotions are dealt with well maybe the rest won't be so bad.

Sometimes, I wouldn't say you overexaggerate your pain, but you make it seem worse because your needs aren't being met.

(Patient K)

As may be expected, medical students discussed the pharmacological management of pain at length. However, they were uncomfortable with different opioids and conversions from one to another and they wanted more training. They reported having been exposed to clinicians who treat pain with different medications and did not understand the reasons for such variations. In addition, they would have appreciated additional exposure to the clinical management of different types of pain, particularly chronic pain. Although the emotional aspect of pain was mentioned and its importance was clear in pain assessment, students wondered how to integrate it in clinical management:

What can we do? Is there counselling? Are there other forms of therapies that we can try other than pharmacology? Or do we also use pharmacology? I just didn't feel like the emotional pain was talked about or covered enough. (Second-year student, focus group 1)

Similarly, students expressed the need to explore alternative therapies apart from pharmacology that could be used to help manage pain, including acupuncture, osteopathic medicine and cognitive-behavioural therapy, among others (Table 2). They did not feel qualified advising patients on the benefits and harms of these complementary approaches. Overall, students wished for more education and practice regarding all aspects of pain management, including pharmacology and alternative methods.

Educators discussed the need to improve the pharmacological knowledge of students and to give them opportunities to practice prescribing pain medications. While knowledge of the WHO ladder for pain management was mentioned as being important, clinicians repeated that 'practice makes perfect', especially in an area as complex as pain management. Knowing which medication to begin treatment with in different individuals was described as the 'art part' in medicine. Participating educators called for more patient involvement in the management of pain:

Many times you must make the patient play an equal part in the decision. What is more of a problem for them? (Anesthesiologist)

They were also straightforward with patients in exposing the variety of options when dealing with pain, as shown in Table 2. Finally, they emphasized the need to focus on interventions that will improve patients' functioning and quality of life, thus involving them in developing management plans and setting priorities.

\section{Communication and the development of a good therapeutic relationship}

While communication is central to developing a good therapeutic relationship in any clinical interaction, it is particularly significant in discussing pain. Patients often feared that their health care providers would not believe their pain was real:

It's hard to explain the pain. When I tell them that I have pain,

I wonder if they think it's all in my head. (Patient A)

They also valued honesty in clinical conversations, while wanting to maintain hope. The majority did not want their physician to act as though they had the perfect treatment, but rather to honestly commit to try to find one together (Table 2). As mentioned previously, finding an attentive clinician had a therapeutic impact for patients:

I think half of the battle was having somebody who would listen, because yes the pain is there and yes they can give me something that could help, but I think once you've achieved the point where someone sat down and listened to what you had to say in terms of what you were feeling, I think that's huge. It's part of a relief. (Patient M)

The importance of establishing a trusting relationship with patients was also particularly significant for students when discussing pain management. They were concerned about patients potentially malingering and exhibiting drug-seeking behaviour, and of being overly suspicious health care providers toward patients experiencing genuine pain. Thus, being able to trust what the patient was saying about his or her experience of pain and expressing this trust so that the patient could be taken seriously was paramount. However, achieving such a relationship was challenging, because they did not feel very well trained at identifying drug-seeking behaviours. In addition, they recognized that establishing shared goals in pain management mattered, especially for complex cases of chronic pain. Discussing patients' expectations and exploring their concerns and fears was central, lest patients do not understand why certain medications are prescribed: 
The treatments are very poorly communicated, so you know, the whole notion of giving psychoactive drugs for pain doesn't mean that the pain is all in your head. (Second-year student, focus group 5)

Many students further mentioned the therapeutic value of acknowledging the pain and validating patients' complaints.

Basic bedside manners were discussed as part of the mentoring work of educators:

My approach is to sit at the bedside and to make eye contact with people. [...] I'm making time for you, either with my eyes or my body language. (Clinical nurse specialist)

Communication was described as a major component of pain management to simultaneously set realistic goals and offer reasonable hope. It was crucial to develop any care plan:

Communication is very important because we first of all have to assess what the goals of the patient are. (Palliative care physician)

Educators frequently repeated that the key to good communication is having the ability to listen to what the patients have to say and to legitimize the pain. They said that patients generally know when their care providers are being attentive and interested (Table 2 ). Thus, they emphasized the importance of adopting a genuine attitude and of committing emotionally. Participating experts were also honest about the emotional burden involved in providing good care to pain patients.

\section{Ethical considerations}

Participating patients had been in situations in which health care providers had cast doubt over the genuineness of their pain complaints, and they profoundly resented these instances:

They should never doubt what patients say about their pain. (Patient B)

They had also been accused of seeking drugs when presenting in the emergency room at their most vulnerable moments. Fibromyalgia patients suffered from providers' lack of knowledge about their condition, as well as from the reputation that often accompanied it:

When it isn't my own doctor honestly, I come for whatever other problem; it is like I am labelled. [...] It's all in your head and you play the game of the disease. (Patient C)

They also mentioned how they often censored themselves and avoided talking about their pain with their loved ones and health care providers, for fear that they would judge them.

Many ethical questions were discussed during the students' focus groups. Students repeatedly expressed concern about the impact of cultural differences on pain expression, yet they did not know how this should be taken into consideration when interpreting people's expression of pain. Their interpretation was also influenced by their own personal experiences, which they admitted was problematic:

So you make a subjective judgment based on your own experience as to how is this... Is this really bad pain? Which is dangerous you know, because I've never had fibromyalgia. I've never had you know, chronic migraines. So it can be a bit tricky.

(Fourth-year student, focus group 3)

They admitted that a certain stigma is associated with being in pain, and acknowledged the negative reactions that are common when faced with patients who recurrently present with complaints of pain.

You can't help feeling kind of annoyed by it, even though you want to be understanding all the time. (Second-year student, focus group 1)

Some attributed this to their own feeling of powerlessness when interventions fail to relieve pain. Students further worried about the level of caution that they should adopt when prescribing pain medications that have an addictive potential, including the inevitability of some malingering. Overall, participating students identified a need for more reflective practice surrounding pain management and communication.
Pain educators knew that many patients presenting with pain are not being legitimized in the health care system. They explained that expressions of pain often trigger a negative reaction in people:

I think there's this instinct in people who hear a complaint of pain to withdraw. (Anesthesiologist)

They also realized that professionals have their own biases toward pain presentations, but insisted that:

Those judgments are meant to be felt and perceived, but not necessarily enter the clinical realm. (Clinical nurse specialist)

They also mentioned that pain is so challenging that professionals will often shy away from their incompetence at treating those patients.

It's very frustrating to deal with the fact that you have to try and potentially fail at treating pain. (Anesthesiologist)

Health care providers admitted to having to be particularly humble when facing the limited success that pain management could yield. Dealing with pain among different cultural communities who had different means of expressing pain also contributed to their clinical challenges. Finally, participating educators recognized the important role of medical schools in preparing students to deal with the risks of prescribing drugs that may lead to addiction without making them overly suspicious.

\section{Institutional context of medical education about pain}

Patients were obviously less worried than professionals about the impact of the institutional setting of pain education on the care that they were receiving. Nonetheless, they did realize that certain specialists were much less comfortable with their complaints of pain:

Even with my oncologist, when I told him I was followed in palliative care for the pain, he was relieved. (Patient A)

They also had a sense of the helplessness of their health care provider when they faced pain as a problem in its own right, rather than simply as the symptom of an acute illness:

About doctors, I think they are very helpless when you come and you say that you have pain and it isn't a given disease. If you have pain because you broke your arm, then they get it. (Patient F)

Overall, patients wished their clinicians had more training and were more resourceful when it came to managing their pain.

It is important to note that, although students' personal experiences with pain were comparable across groups (Table 1), there were differences between the answers of second-year and fourth-year students, particularly when discussing the realities of practice. Second-year students tended to be more idealistic and to talk about their own personal experiences with pain, while toward the end of their undergraduate training, students had been more fully socialized into their professional roles. Fourth-year students admitted that pain had not been their priority during their clinical training, whereby a fourth-year student said:

The pain is not going to kill the patient [...] It's not the focus of what we are doing here. (Table 2)

Another fourth-year student summmarized the issue well when he discussed the existence of a breach between patients' concerns and their own professional priorities, explaining that their job as medical professionals "is not to miss a critical diagnosis" (focus group 3). From the perspective of their medical training, they would, thus, be satisfied to walk away knowing that the "pain is nothing to worry about", while this is often less than satisfactory from a patient's perspective.

Educators were acutely aware of the importance of mentorship in learning adequate pain management. They believed that all clinical teachers had the responsibility to demonstrate the importance of pain management (Table 2), adding that medical students perceive their mentors' reluctance to address pain as a part of their practice very early on:

Their mentorship for pain on the surgical service is abysmal. It's just seen as a byproduct and a nuisance of whatever therapy or experience the patient is having. By and large when it does become chronic most surgeons would rather keep the patients 
as far away as possible from themselves. I think they do communicate that to the medical students. (Anesthesiologist)

The educators repeated the need for additional exposure to good role models in taking care of patients in pain. In reality, they knew that many clinicians are afraid to deal with problems such as chronic pain because they do not know what to do with these patients:

They do as if it [pain] doesn't exist, which is totally beyond comprehension. The most common, the most prevalent complaint on earth and people just disregard it. (Anesthesiologist)

Finally, participating clinicians recognized the impact of the hospital setting in shaping undergraduate pain education; the majority of their training occurs in the hospital, while much of the practice of pain management will occur in outpatient settings.

\section{DISCUSSION}

In the present investigation, we aimed to document the concerns of pain stakeholders about medical students' training in pain assessment and management. Being the first interpretive investigation on this topic, the results reveal, first and foremost, a clear consensus among participants (ie, patients, students and educators) that training about pain in undergraduate medical curricula is inadequate, a deficit that then leads to poor management of pain in clinical practice (2). Our study further makes many specific contributions to our knowledge about important areas of learning about pain.

The first contribution concerns the assessment of pain. Medical students wanted to learn how to properly use pain scales and questionnaires, and to venture beyond the traditional history-taking about pain to include its psychosocial aspects. Patients and experts concurred about a need for a more complete assessment that can address the multidimensional experience of pain. More specifically, the translation of subjective pain experiences into clinical evaluation and treatment represented a challenge for trainees. Students often reported using pain scales to compare 'absolute levels' of pain across patients with similar conditions, rather than using them within a single patient to assess the effectiveness of a given intervention. While numerical and visual pain scales are more reliable than verbal descriptions in detecting changes in the level of acute pain experienced by patients, the complexity of chronic pain can be better explored with multidimensional, qualitative tools that also take into account the functional, psychological and social impact of pain (29). The importance of psychosocial assessments should come as no surprise because research in the context of chronic low back pain, among other contexts, has demonstrated that psychological factors are involved in the transition from acute to chronic pain (30).

The second contribution of the study pertains to pain management. Participating students called for more exposure and practice dealing with standard pharmacological options, as well as more information about interdisciplinary and alternative options such as osteopathic medicine, lifestyle changes and cognitive-behavioural therapy. In this regard, educators perceived exposure to mentors proficient in pain management as a crucial part of medical education. The pharmacological management of pain represents an 'art' in medical practice, and can be guided by recent interpretations of the WHO ladder (31). The training that students receive also needs to reflect the increasing popularity of complementary and alternative medicines in the management of chronic health problems. Participating patients expected medical professionals to be knowledgeable about these different types of management and to incorporate them in their treatment recommendations.

Third, the present study supports the concept that a patient-centred approach supported by good communication skills is central when caring for patients in pain. As Leila et al (32) argued, learners need to be provided with the tools to develop appropriate interviewing skills about pain. In effect, all participants perceived communication about pain to be very important, recognizing both the therapeutic value of acknowledging pain in itself and the need to establish trusting relations when using medications with addictive potential. The development of good communication skills was also considered to be essential to develop a shared treatment plan with patients and explore their understanding of therapeutic options. It has been demonstrated that training internists and residents to use shared decision-making when approaching chronic opioid use for chronic noncancer pain significantly increases the satisfaction of physicians contending with this common and challenging clinical problem (33).

A fourth contribution of our research was to highlight the ethical challenges caused by biases and prejudices of health care providers in exploring subjective feelings of pain, especially among different cultural groups, in which they were perceived as a hurdle to establishing effective therapeutic relationships. Training in professionalism has been incorporated in medical education (34), and relieving pain and suffering has been perceived as a professional responsibility of physicians. The acceptability of diverse pain expressions will certainly vary in different cultural communities; how to cautiously incorporate this into pain assessments should be discussed with students during training to avoid prejudice and discrimination in clinical practice. A study regarding medical students' perception of suffering further demonstrated that students did not believe that they were well prepared to deal with the feelings that encountering suffering would generate in their practice (35). Similarly, there was widespread understanding among our participants that caring for patients in pain is a very demanding professional activity that can trigger negative reactions in health care providers; medical students should be invited to reflect on their personal reactions to pain presentations and on how these reactions may affect pain management.

Our fifth contribution highlights the impact of the educational environment on training in pain assessment and management. As established in other studies (36), a close examination of students' opinions and narratives offers a window into the 'hidden curriculum' of medical school $(37,38)$. In the context of education about pain, this 'hidden curriculum' was mentioned as reducing the importance of pain management because pain tended to be approached as a nuisance rather than as an important symptom and potential disease on its own. Students' exposure to mentors who took the time to practice good pain management in outpatient settings was deficient, in the opinion of participants. As long as proper pain assessment and management do not represent a core objective in undergraduate medical education, students' expertise in this area will suffer.

The present study had several limitations that should be addressed. It was conducted at a single academic institution (McGill University); this may limit the transferability of the findings to other medical schools. However, the issues we have identified are by no means unique to any one school, and deficiencies in pain education are widespread; therefore, we posit that similar results would be observed if the study were to be conducted elsewhere. We also recognize that our sampling frame may give rise to bias; students, patients and professionals were, to some extent, self-identified, and may, therefore, hold a particular interest in conveying a message regarding pain education. This may also be supported by the fact that $68 \%$ of participating patients believed their pain management to be inadequate, $21 \%$ to $28 \%$ of the students actually experienced chronic pain themselves and the professionals were all employed in a chronic pain teaching unit. This potential source of bias is a particular concern with qualitative work in which a random selection of participants is not performed, but we believe that the key finding of several broad themes that can and should be addressed in pain curricula remains valid.

In closing, defining pain stakeholders' main concerns, the present study has also helped define the aspects of pain assessment, management and communication that would need to be included in the undergraduate curriculum to improve patient care and better prepare medical professionals to deal with one of the most common presenting symptoms they will encounter during their career. Answering the call for innovative education technologies to tackle the global challenge of pain management education (39), the next step of the research project has been to embed the identified themes in the design of an e-tool using virtual patient cases for medical undergraduate training, called the Pain Education e-Tool. It is a flexible, web-based program that may fit into 
crowded curricula because different parts of the cases and resources about pain could be referred to either by educators or by students on their own during their training (40). Currently under evaluation, the Pain Education e-Tool has been conceived and designed to provide students with the skills required to gather appropriate information about pain, to select therapeutic options from a wide spectrum not limited to pharmacological treatments and including interprofessional collaboration, to develop a mutual and trusting relationship with patients and, finally, to become aware of their own biases and prejudice toward patients with pain. As our qualitative study has emphasized, these represent valuable learning objectives in the pursuit of achieving better education about pain for patients, medical students and educators, and deserve further examination in future investigations.

\section{SUMMARY}

The present qualitative descriptive study used data from interviews and focus groups to explore areas of education relating to pain management

\section{REFERENCES}

1. International Association for the Study of Pain. <www.iasp-pain. org//AM/Template.cfm?Section=Home $>$ (Accessed January 2011).

2. Moulin DE, Clark AJ, Speechley M, Morley-Forster PK. Chronic pain in Canada - prevalence, treatment, impact and the role of opioid analgesia. Pain Res Manag 2002;7:179-84.

3. Todd KH, Ducharme J, Choiniere M, et al. Pain in the emergency department: Results of the pain and emergency medicine initiative (PEMI) multicenter study. J Pain 2007;8:460-6.

4. Mehta S, Burry L, Fischer S, et al. Canadian survey of the use of sedatives, analgesics, and neuromuscular blocking agents in critically ill patients. Crit Care Med 2006;34:374-80.

5. Mitera G, Fairchild A, DeAngelis C, et al. A multicenter assessment of the adequacy of cancer pain treatment using the pain management index. J Palliat Med 2010;13:589-93.

6. Kirou-Mauro AM, Hird A, et al. Has pain management in cancer patients with bone metastases improved? A seven-year review at an outpatient palliative radiotherapy clinic. J Pain Symptom Manage 2009;37:77-84.

7. Boulanger A, Clark AJ, Squire P, Cui E, Horbay GLA. Chronic pain in Canada: Have we improved our management of chronic noncancer pain? Pain Res Manag 2007;12:39-47.

8. Morley-Forster PK, Clark AJ, Speechley M, Moulin DE. Attitudes toward opioid use for chronic pain: A Canadian physician survey. Pain Res Manag 2003;8:189-94.

9. Rose L, Smith O, Gélinas C, et al. Critical care nurses' pain assessment and management practices: A survey in Canada. Am J Crit Care 2012;21:251-9.

10. Watt-Watson J, Stevens B, Garfinkel P, Streiner D, Gallop R. Relationship between nurses' pain knowledge and pain management outcomes for their postoperative cardiac patients. J Adv Nurs 2001;36:535-45.

11. Sinatra R. Causes and consequences of inadequate management of acute pain. Pain Med 2010;11:1859-71.

12. Notcutt W, Gibbs G. Inadequate pain management: Myth, stigma and professional fear. Postgrad Med J 2010;86:453-8.

13. Stevens DL, King D, Laponis R, et al. Medical students retain pain assessment and management skills long after an experiential curriculum: A controlled study. Pain 2009;145:319-24.

14. Hunter J, Watt-Watson J, McGillion M, et al. An interfaculty pain curriculum: Lessons learned from six years experience. Pain 2008;140:74-86.

15. Hanna MN, Donnelly MB, Montgomery CL, Sloan PA. Perioperative pain management education: A short structured regional anesthesia course compared with traditional teaching among medical students. Reg Anesth Pain Med 2005;30:523-8.

16. Watt-Watson J, Hunter J, Pennefather P, et al. An integrated undergraduate pain curriculum, based on IASP curricula, for six Health Science Faculties. Pain 2004;110:140-8.

17. Wilson JF, Brockopp GW, Kryst S, Steger H, Witt WO. Medical students' attitudes toward pain before and after a brief course on pain. Pain 1992;50:251-6.

18. Watt-Watson J, McGillion M, Hunter J, et al. A survey of prelicensure pain curricula in health science faculties in Canadian universities. Pain Res Manag 2009;14:439-44. that need improvement from the perspective of stakeholders, ie, patients, medical students and educators. All participants recognized a need for additional medical education about pain assessment and management. Five themes were identified to be important: the assessment of physical and psychosocial aspects of pain; the clinical management of pain with pharmacology and alternative therapies; communication and the development of good therapeutic relationships; the ethical considerations surrounding pain; and the institutional context of medical education about pain.

ACKNOWLEDGEMENTS: The authors thank all participating patients, students and educators for their time and insight.

FUNDING: This study was funded by an unrestricted educational grant from Purdue Pharma.

19. Mezei L, Murinson BB, Team TJHPCD. Pain education in North American medical schools. J Pain 2011;12:1199-208.

20. Charlton JE, ed. Core Curriculum for Professional Education in Pain, 3rd edn. Washington: IASP Press, 2005.

21. Turner GH, Weiner DK. Essential components of a medical student curriculum on chronic pain management in older adults: Results of a modified Delphi process. Pain Med 2002;3:240-52.

22. Yanni LM, Priestley JW, Schlesinger JB, Ketchum JM, Johnson BA, Harrington SE. Development of a comprehensive e-learning resource in pain management. Pain Med 2009;10:95-105.

23. Sandelowski M. Whatever happened to qualitative description? Res Nurs Health 2000;23:334-40.

24. Sandelowski M. What's in a name? Qualitative description revisited. Res Nurs Health 2010;33:77-84.

25. Rubin HJ, Rubin IS. Qualitative Interviewing: The Art of Hearing Data, 2nd edn. Thousand Oaks: Sage Publications Inc, 2004.

26. Krueger RA, Casey MA. Focus Groups: A Practical Guide for Applied Research. 3rd edn. Thousand Oaks: Sage Publications Inc, 2000.

27. Braun V, Clarke V. Using thematic analysis in psychology. Qualitative Research in Psychology 2006;3:77-101.

28. HyperResearch. <www.researchware.com/products/hyperresearch. html> (Accessed August 2012).

29. Breivik H, Borchgrevink PC, Allen SM, et al. Assessment of pain. Br J Anaesth 2008;101:17-24.

30. Pincus T, Burton AK, Vogel S, Field AP. A systematic review of psychological factors as predictors of chronicity/disability in prospective cohorts of low back pain. Spine 2002;27:E109-20.

31. Vargas-Schaffer $\mathrm{G}$. Is the $\mathrm{WHO}$ analgesic ladder still valid? Twenty-four years of experience. Can Fam Physician 2010;56:514-7, e202-5.

32. Leila N-M, Pirkko H, Eeva P, Eija K, Reino P. Training medical students to manage a chronic pain patient: Both knowledge and communication skills are needed. Eur J Pain 2006;10:167-70.

33. Sullivan MD, Leigh J, Gaster B. Brief report: Training internists in shared decision making about chronic opioid treatment for noncancer pain. J Gen Intern Med 2006;21:360-2.

34. Swick HM, Szenas P, Danoff D, Whitcomb ME. Teaching professionalism in undergraduate medical education. JAMA 1999;282:830-2.

35. Egnew TR, Schaad DC. Medical trainee perceptions of medical school education about suffering: A pilot study. J Palliat Med 2009;12:929-35.

36. Karnieli-Miller O, Vu TR, Holtman MC, Clyman SG, Inui TS. Medical students' professionalism narratives: A window on the informal and hidden curriculum. Acad Med 2010;85:124-33.

37. Hafferty FW. Beyond curriculum reform: Confronting medicine's hidden curriculum. Acad Med 1998;73:403-7.

38. Lempp H, Seale C. The hidden curriculum in undergraduate medical education: Qualitative study of medical students' perceptions of teaching. BMJ 2004;329:770-3.

39. Devonshire E, Siddall PJ. Joining forces: Collaborating internationally to deliver high-quality, online postgraduate education in pain management. Pain Res Manag 2011;16:411-5.

40. Puljak L, Sapunar D. Web-based elective courses for medical students: An example in pain. Pain Med 2011;12:854-63. 


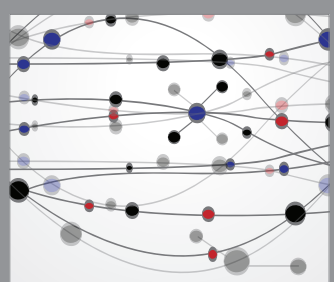

The Scientific World Journal
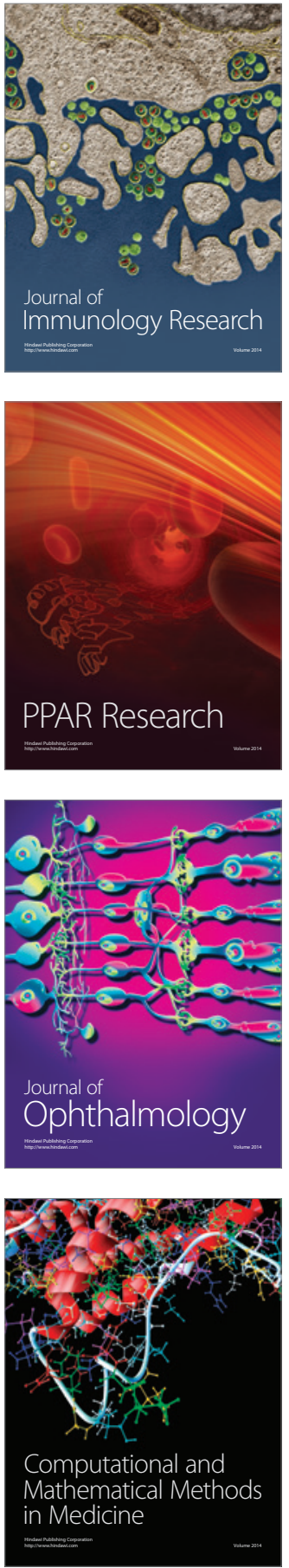

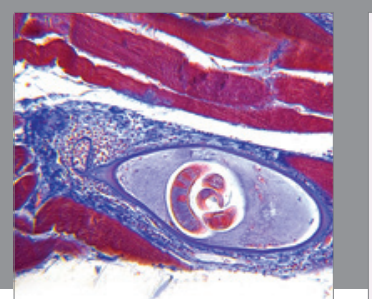

Gastroenterology Research and Practice

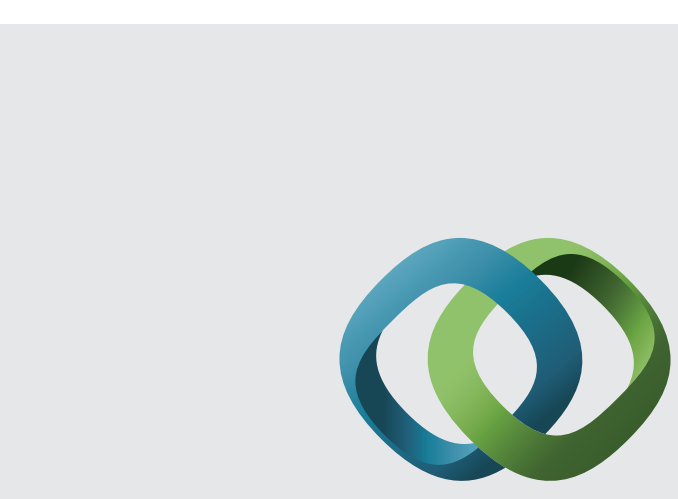

\section{Hindawi}

Submit your manuscripts at

http://www.hindawi.com
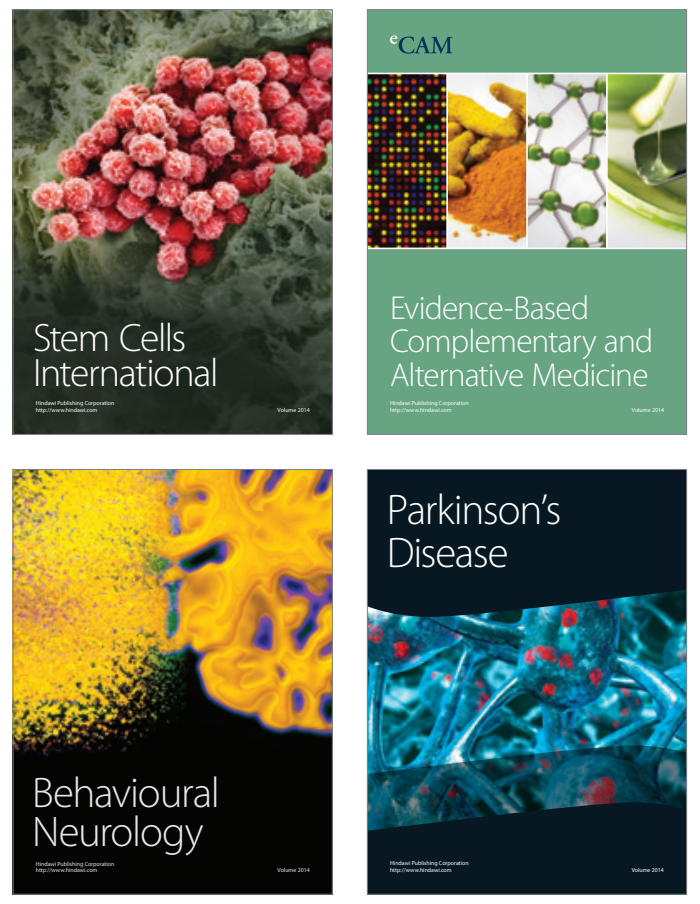
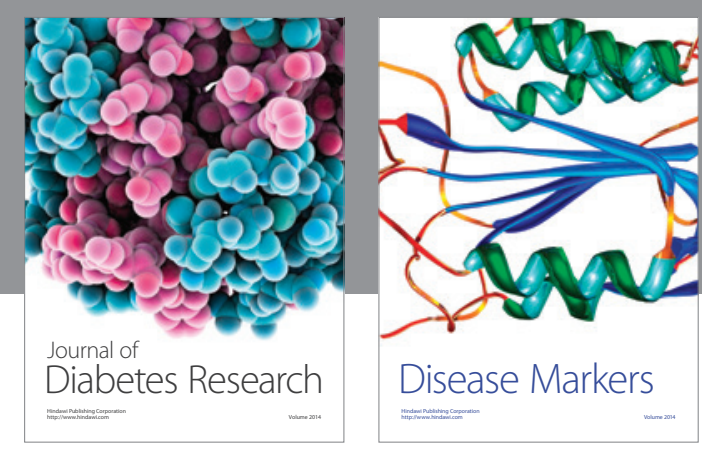

Disease Markers
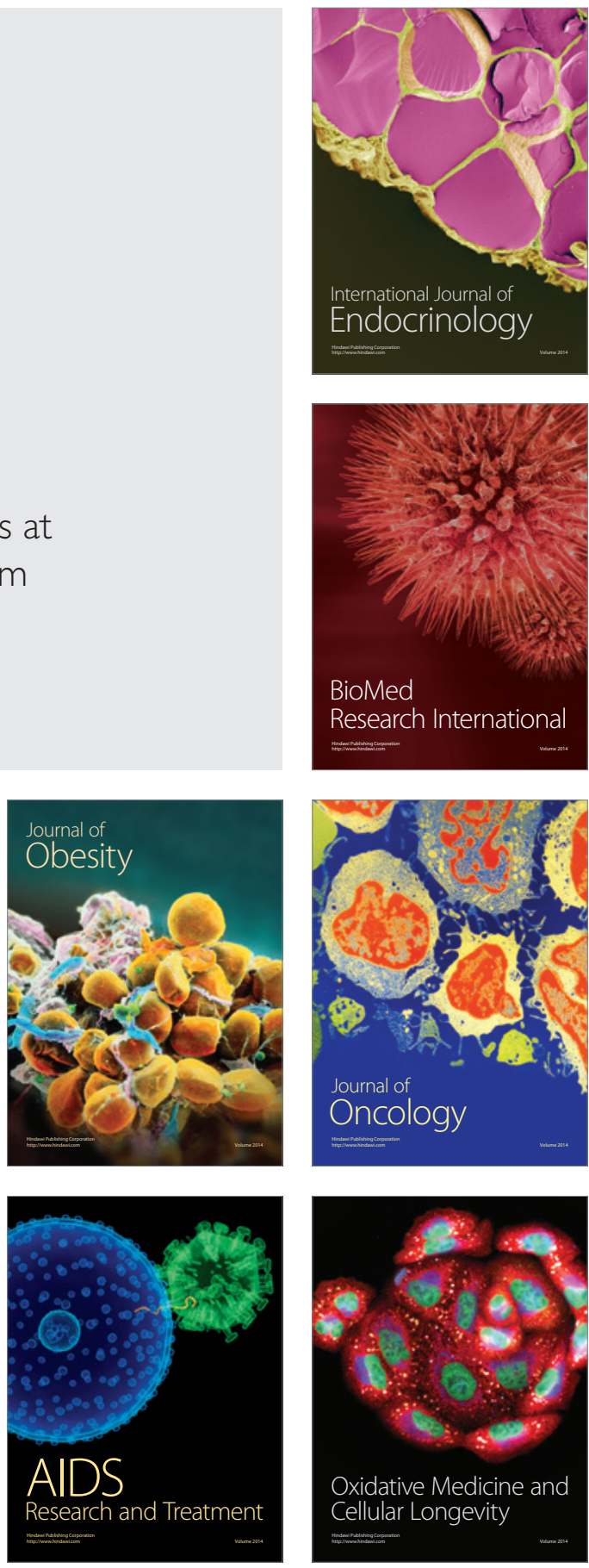